\title{
Determinación cuantitativa de bactericidas en cosméticos "dermoprotectores"
}

\author{
Por N. Crespo González y D. Prada Rodríguez \\ Departamento de Química Analítica. Facultad de Ciencias. \\ Universidad de La Coruña. Campus de Zapateira. 15071 (La Coruña).
}

\section{RESUMEN}

Determinación cuantitativa de bactericidas en cosméticos "dermoprotectores"

Se describe un método rápido, sencillo y reproducible para la determinación cuantitativa de los bactericidas más utilizados en la industria cosmética del mercado español con fines dermoprotectores.

El método es aplicable tanto a jabones sólidos como a disoluciones de tensioactivos, variando en este caso tan sólo el método de extracción.

Se ha elegido la cromatografía de gases para la elaboración de este método por ser una técnica rápida y asequible, además de permitir la resolución simultánea de todos los bactericidas estudiados.

PALABRAS-CLAVE: Bactericida (determinación) - Derivatización Extracción - Gel - Jabón - Tensioactivo.

\section{SUMMARY}

Quantitative determination of antimicrobial preservatives in cosmetics called "dermoprotectors"

A rapid, easy and reproducible method is described for the quantitative determination of the usual antimicrobial preservatives used in the cosmetic industry in the Spanish market with a dermoprotector claim.

The method is also useful for soap bars and for surfactant solutions in this last case the method of extraction is the only change.

Gas Chromatography has been chosen as the analytical process for the set up of this method because it is a rapid and available technique, and it allows the simultaneous resolution of all the studied preservatives.

KEY-WORDS: Antimicrobial preservative (determination) - Derivatization - Extraction - Gel - Soap - Surfactant.

\section{INTRODUCCION}

La actitud hacia el cuidado de la piel ha variado en los últimos años. Bajo la contínua insistencia de mensajes en los medios de comunicación sobre temas de prevención de enfermedades y de contagios, cada vez más este sentimiento se hace patente en amplios sectores de la población y ha dado lugar al uso de productos con propiedades protectoras de la piel.

En los últimos años se ha producido en España un espectacular progreso en el uso de los llamados jabones o geles dermoprotectores.

La única diferencia con los productos tradicionales, al menos en el mercado nacional, consiste en una mejor elección del sistema tensioactivo en el sentido de una me- nor agresividad cutánea y $\mathrm{pH}$ más cercano al del manto ácido de la piel; la incorporación de sustancias que actúen como reengrasantes $y / 0$ hidratantes, y por último, pero no menos importante, la adición de productos bactericidas o bacteriostáticos cuya función no es sólo la de conservar el cosmético, sino la de ejercer una cierta acción antimicrobiana que debe proteger la piel de infecciones y contagios.

Es importante resaltar que un antiséptico utilizado en pequeñas concentraciones, pero diariamente, puede provocar efectos no deseados sobre el organismo, esto se debe, principalmente, a la penetración de este tipo de productos a través de la piel. "Simon (1978)", "Marzulli (1973)".

A causa de este fenómeno surge el desarrollo de los productos llamados "dermoprotectores", bajo la esperanza de que la sustantividad del producto sobre la piel del usuario sea lo suficientemente eficaz y duradera como para impedir la contaminación de la misma por los microorganismos a los que está expuesta, principalmente en locales de uso público.

La reciente legislación "B.O.E. n. 9 95, de 20 de abril de 1988" reclama establecer un método cualitativo y cuantitativo rápido y reproducible para la determinación de dichos compuestos, ya que resulta imprescindible incluir en la etiqueta la cantidad añadida de los productos que se utilizan como reclamos publicitarios, en este caso, los bactericidas.

Aunque en el mercado español existe una gran variedad de agentes conservantes, sólo unos pocos de ellos se utilizan con fines dermoprotectores en los productos cosméticos que utilizan esta denominación.

Existe una gran cantidad de información bibliográfica referida a la identificación de compuestos con actividad antibacteriana, utilizando numerosas y variadas técnicas analíticas, debido a la diversidad de compuestos que existen con estas propiedades.

Entre los métodos más utilizados se encuentra la cromatografía en capa fina como técnica de separación, y la cromatografía gaseosa como técnica de cuantificación. "Liem y col (1977)" analizan IRGASAN mediante esta técnica.

Otros métodos propuestos, dependiendo de la natu- 
raleza del bactericida, son: Fluorimetría "Ackman y Burguer (1963)"; determinaciones polarográficas "Elving (1948)"; Espectrofotometría ultravioleta "Shepard (1974)"; HPLC "Montarella (1988)".

En este estudio se utiliza la técnica de cromatografía en fase gaseosa, previa extracción de los bactericidas a estudiar por métodos líquido-líquido y sólido-líquido, para la identificación y cuantificación de los compuestos. Se trata de un método práctico y útil para resolver mezclas de bactericidas presentes en formulaciones de geles y jabones.

\section{PARTE EXPERIMENTAL}

El desarrollo del método propuesto se ha hecho en base a un estudio previo de los jabones y geles que se encuentran en el mercado con formulaciones dermoprotectoras, llegando a la conclusión de que el grupo de bactericidas empleados se reduce principalmente a cuatro: 2-Bromo-2-Nitropropano-1,3-diol (Bronopol); 2,4,4'-tricloro-2'-hidroxifeniléter (Irgasán); Alcohol 2,4-diclorobencílico (Myacide) y derivados del ácido 10-undecilénico, (principalmente la dietanolamida del mismo).

Por esta causa, este trabajo se centra en la determinación de estos cuatro compuestos presentes, en mezclas o de forma aislada, en distintas formulaciones tanto líquidas como sólidas (geles de baño y jabones de tocador).

En la elección de la técnica instrumental, la cromatografía en fase gaseosa, se han tenido en cuenta dos factores: por un lado, esta técnica es de uso común en las industrias cosméticas; por otro, tres de los bactericidas estudiados (Bronopol, Myacide e Irgasán) presentan en su molécula grupos hidroxilo que pueden ser fácilmente acetilados o silanizados, convirtiéndolos en productos resolubles por esta técnica.

El cuarto bactericida estudiado, el ácido undecilénico, $y$, en particular el derivado más utilizado, la dietanolamida, presenta un problema distinto. Esta última puede ser acetilada, pero de esta forma el análisis quedaría reducido a uno sólo de los posibles derivados del mismo. Por esta causa se ha optado por formar el éster metílico del ácido 10-undecilénico.

La conversión de la amida en el éster del ácido puede hacerse realizando la hidrólisis ácida de la amida con $\mathrm{HCl}$ en Metanol "Morrissette (1965)", y esterificando el ácido obtenido por reacción con Metanol en presencia de Trifluoruro de Boro "Metcalfe (1959)".

En este caso, se ha optado por el método de transformación directa de etanolamidas de ácidos grasos en ésteres metílicos, propuesta por "Lee y Putnam (1965)", sobre el trabajo de "Peisker (1964)".

Los bactericidas con grupos alcohólicos en la molécula (Bronopol, Myacide e Irgasán) presentan la característica de ser los suficientemente solubles en disolventes apolares como para poder ser retirados de la matriz por métodos de extracción líquido-líquido y sólido-líquido. En los cosméticos objeto de estudio, los compuestos mencionados se encuentran formando combinaciones Bronopol-Myacide (en geles) y Myacide-Irgasán (en jabones) La causa de esta combinación es el efecto sinérgico bactericida (Bronopol e Irgasán) / fungicida (Myacide).
La dietanolamida del ácido 10-undecilénico, no es soluble en disolventes orgánicos, por lo que se describe a continuación la determinación de los tres primeros y, seguidamente, la determinación de los derivados del ácido undecilénico.

\section{Extracción de los bactericidas de los jabones só-} lidos:

Se procedió a la extracción sólido-líquido de $10 \mathrm{~g}$ de jabón por medio de un soxhlet de $50 \mathrm{ml}$ de capacidad, durante tres horas. El jabón debe ser molido en un molinillo común de hélice. El disolvente empleado fue éter etílico de calidad cromatográfica, igual que el utilizado en la preparación de las disoluciones patrón.

\section{Extracción de los bactericidas de los geles:}

Se efectuó una extracción líquido-líquido, disolviendo $15 \mathrm{~g}$ de gel en una disolución al $20 \%$ de $\mathrm{NaCl}$. Se utilizaron tres porciones de éter etílico de $50 \mathrm{ml}$ como disolvente extractor.

Los extractos etílicos combinados fueron concentrados a sequedad, redisueltos en la mezcla acetilante, anhídrido acético-piridina $1: 1(\mathrm{v} / \mathrm{v})$ durante $10 \mathrm{~min}$ a $60^{\circ} \mathrm{C}$, extraídos los compuestos acetilados y lavadas las fases etéreas. Posteriormente se procedió al análisis por cromatografía en fase gaseosa.

Como método de cuantificación se utilizó el del patrón interno, utilizando como tal el hexadecano (Carlo Erba), teniendo en cuenta que cumple las condiciones requeridas para tal fin.

Las disoluciones patrón fueron preparadas a partir de los bactericidas comerciales utilizados en los jabones es tudiados, suministrados por los proveedores correspondientes.

Determinación de la dietanolamida del ácido 10-undecilénico:

Se realiza la conversión directa de dietanolamida del ácido 10-undecilénico, al éster metílico del mismo ácido, a elevada temperatura y bajo presión, por lo que es necesario disponer de un bloque de calentamiento (Heating unit, RB-01; Research and Industrial Instuments Company).

El método consiste en introducir $15 \mathrm{~g}$ de muestra en un tubo de vidrio calibrado de 4"x7/6" (Excelco) al que se añaden $3 \mathrm{ml}$ del reactivo metilante (Cloroformo-MetanolAcido sulfúrico 100:100:1 v/v). El tubo de vidrio se introduce en el de acero y éste en la carcasa cerrado herméticamente, y se mantiene a $185^{\circ} \mathrm{C}$ durante $15 \mathrm{~min}$. Trans currido ese tiempo, se retiran los tubos, se enfrían bajo corriente de agua y el contenido del tubo se concentra en baño de vapor a $1,5 \mathrm{ml}$, tras lo que se realiza una extracción líquido-líquido con éter etílico.

Este procedimiento se llevó a cabo, por un lado, con un jabón líquido que contenía dietanolamida del ácido 10-undecilénico, y por otro, con la propia dietanolamida suministrada por la casa proveedora que se distribuye en disolución al $50 \%$.

Los extractos acetilados o esterificados fueron cromatografiados utilizando un cromatógrafo Perkin Elmer, mo- 
delo 8310 , equipado con una sola columna y detector de ionización de llama, con compensación automática de la línea de base para trabajos a temperatura programada.

Las columnas cromatográficas seleccionadas son de $2 \mathrm{~m} \times 1 / 8$ ", con $2 \%$ de OV-101 sobre Chromosorb G-AW DMCS, 80/100 mesh.

Los métodos cromatográficos empleados se detallan en la Tabla I.

Tabla I

Método I Método II Método III

Temp. Inicial

Temp. Final

Bronopol y Hyacide Irgasán y Hyacide Amida undecilenico

Isoterma Temp. Inicial Isoterma Temp. Final Rampa Calentamiento Flujo Nitrógeno

$\begin{array}{ccc}120^{\circ} \mathrm{C} & 120^{\circ} \mathrm{C} & 120^{\circ} \mathrm{C} \\ 210^{\circ} \mathrm{C} & 210^{\circ} \mathrm{C} & 160^{\circ} \mathrm{C} \\ 3 \mathrm{~min} & 3 \mathrm{~min} & 3 \mathrm{~min} \\ 1 \mathrm{~min} & 6 \mathrm{~min} & 4 \mathrm{~min} \\ 10^{\circ} \mathrm{C} / \mathrm{min} & 10^{\circ} \mathrm{C} / \mathrm{min} & 4^{\circ} \mathrm{C} / \mathrm{min} \\ 35 \mathrm{ml} / \mathrm{min} & 35 \mathrm{ml} / \mathrm{min} & 35 \mathrm{ml} / \mathrm{min}\end{array}$

\section{RESULTADOS}

El método descrito fue empleado para la determinación sistemática en 179 geles de una mezcla de Bronopol y Myacide, en 43 jabones sólidos de una mezcla de Myacide e Irgasán, y de dietanolamida del ácido undecilénico en 20 geles.

Por este motivo se programaron tres métodos cromatográficos distintos dependiendo de la mezcla de bactericidas a analizar. Es importante destacar que los métodos cromatográficos que figuran en la Tabla I son los de menor duración en tiempo real de cromatograma, para las mezclas de bactericidas propuestas, pero al diferenciarse tan sólo en la programación de temperaturas, se puede establecer un método único que resuelva todos los bactericidas estudiados, ya que como se puede comprobar, el resto de los parámetros cromatográficos son constantes para todos los métodos.

Se presentan en las figuras 1,2 y 3 cromatogramas correspondientes a un jabón líquido (Bronopol y Myacide), un jabón sólido (Irgasán y Myacide) y un jabón líquido (Dietanolamida del ácido 10-undecilénico).

\section{CROMATOGRAMA DE JABON LIQUIDO}

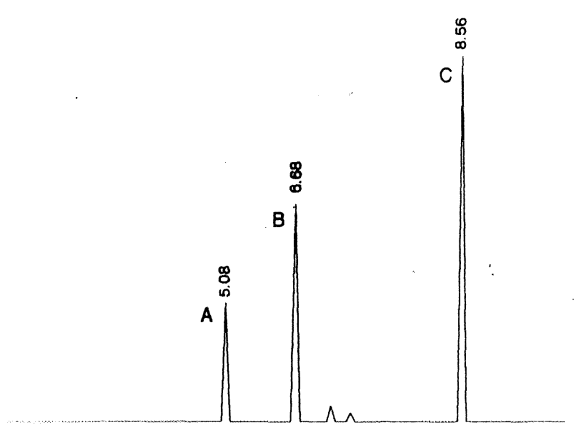

Figura 1

Cromatograma obtenido para una muestra de gel que contenia una mezcla de Bronopol y Myacide. (A) Bronopol, (B) Myacide, (C) Hexadecano. Las condiciones cromatográficas se detallan en la Tabla 1 .

\section{CROMATOGRAMA DE JABON SOLIDO}

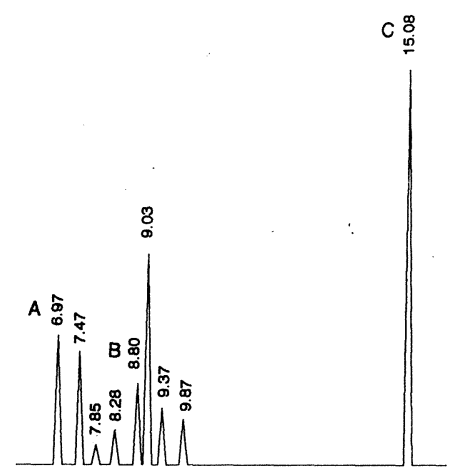

Figura 2

Cromatograma obtenido para una muestra de jabón sólido que contenia una mezcla de Myacide e Irgasan. (A) Myacide, (B) Hexadecano, (C) Irgasan. Las condiciones cromatográficas se detallan en la Tabla I.

CROMATOGRAMA DE JABON LIQUIDO

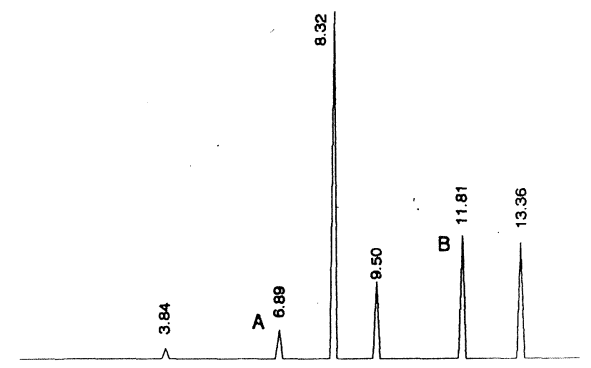

Figura 3

Cromatograma obtenido para una muestra de gel que contenía Dietanolamida del ácido 10-undecilénico. (A) Ester metílico del ácido 10-undeciléniCo, (B) Hexadecano.

Las condiciones cromatográficas se detallan en la Tabla I.

\section{CROMATOGRAMA DE PATRÓN DE BACTERICIDAS}

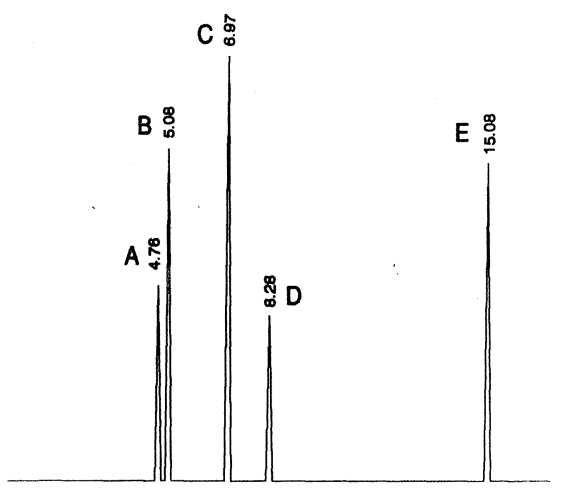

Figura 4

Cromatograma obtenido para un patrón de bactericidas. Método II, Tabla I. (A) $0,4 \% \mathrm{w} / \mathrm{w}$ ácido undecilénico; (B) $0,4 \% \mathrm{w} / \mathrm{w}$ Bronopol; (C) $0,4 \% \mathrm{w} / \mathrm{w}$ Myacide; (D) $0,4 \%$ w/w Hexadecano; (E) $0,4 \%$ w/w Irgasán. 
En la figura 4 se muestra un cromatograma patrón para los cuatro bactericidas estudiados, utilizando como método cromatográfico el señalado en la Tabla I como METODO II, y en el que se demuestra la posibilidad de poder resolverlos simultáneamente.
En las figuras 5, 6 y 7 se presentan los datos correspondientes a la aplicación del método descrito al análisis sistemático de geles y jabones.

\section{DETERMINACION DE MYACIDE Y BRONOPOL EN 50 MUESTRAS DE GEL}

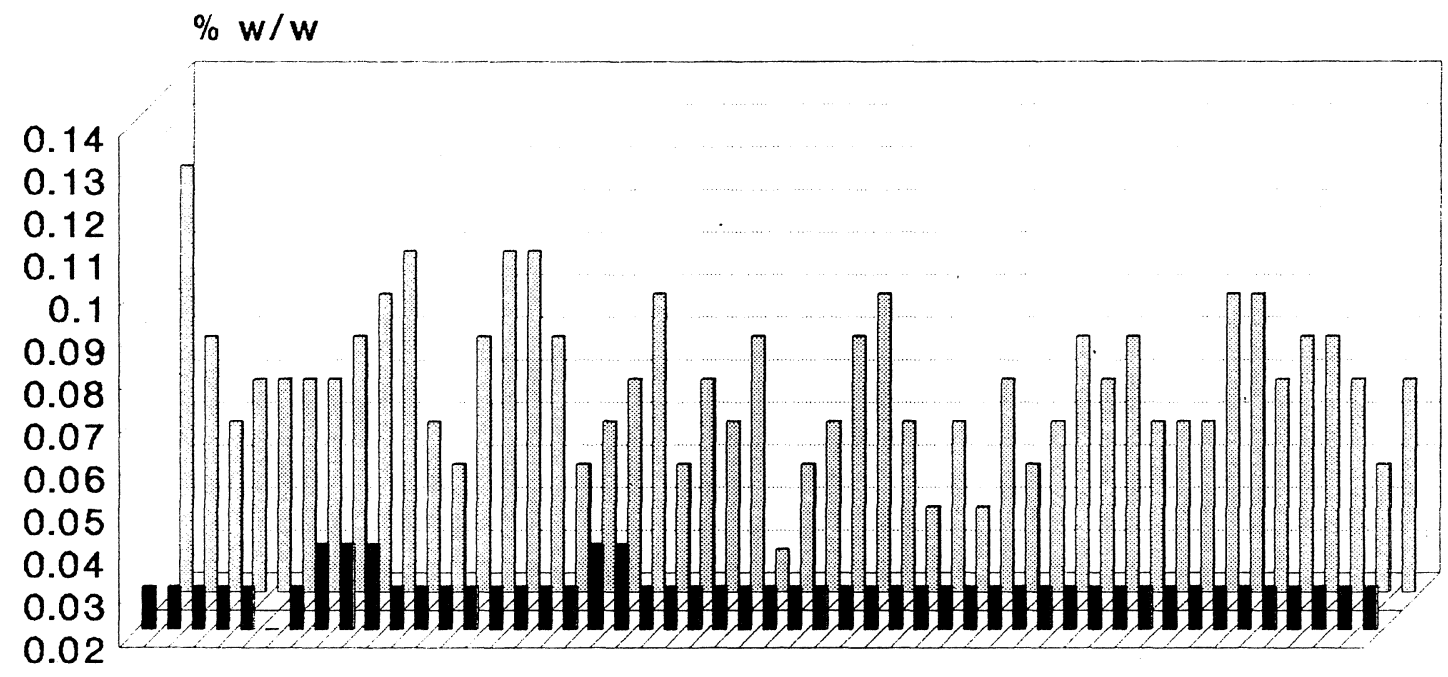

№ MUESTRA

MYACIDE

BRONOPOL

Figura 5 


\section{DETERMINACION DE MYACIDE E IRGASAN \\ EN 43 MUESTRAS DE JABON}

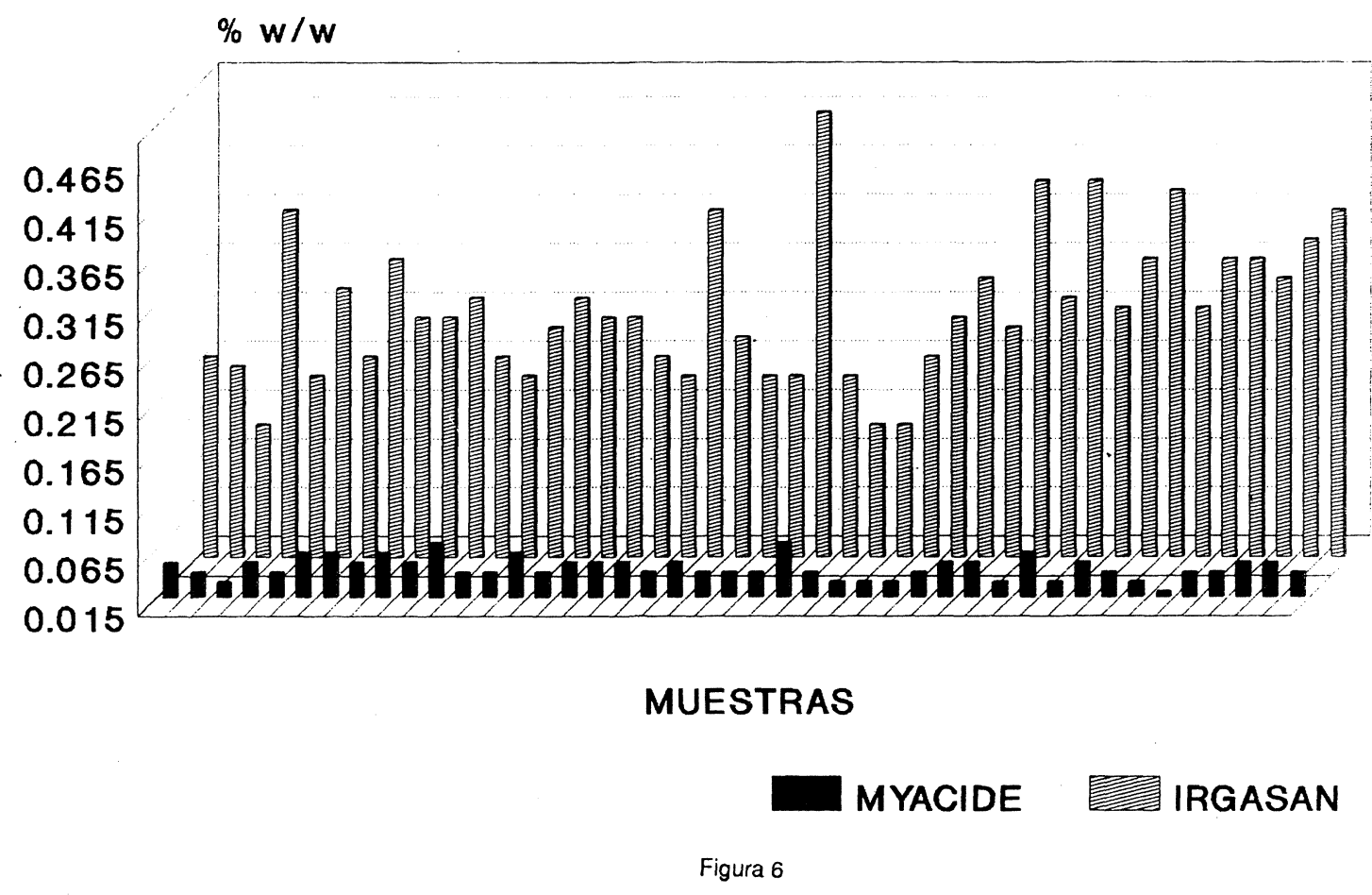

\section{DETERMINACION DE \\ ACIDO 10-UNDECILENICO \\ 20 MUESTRAS DE GEL}

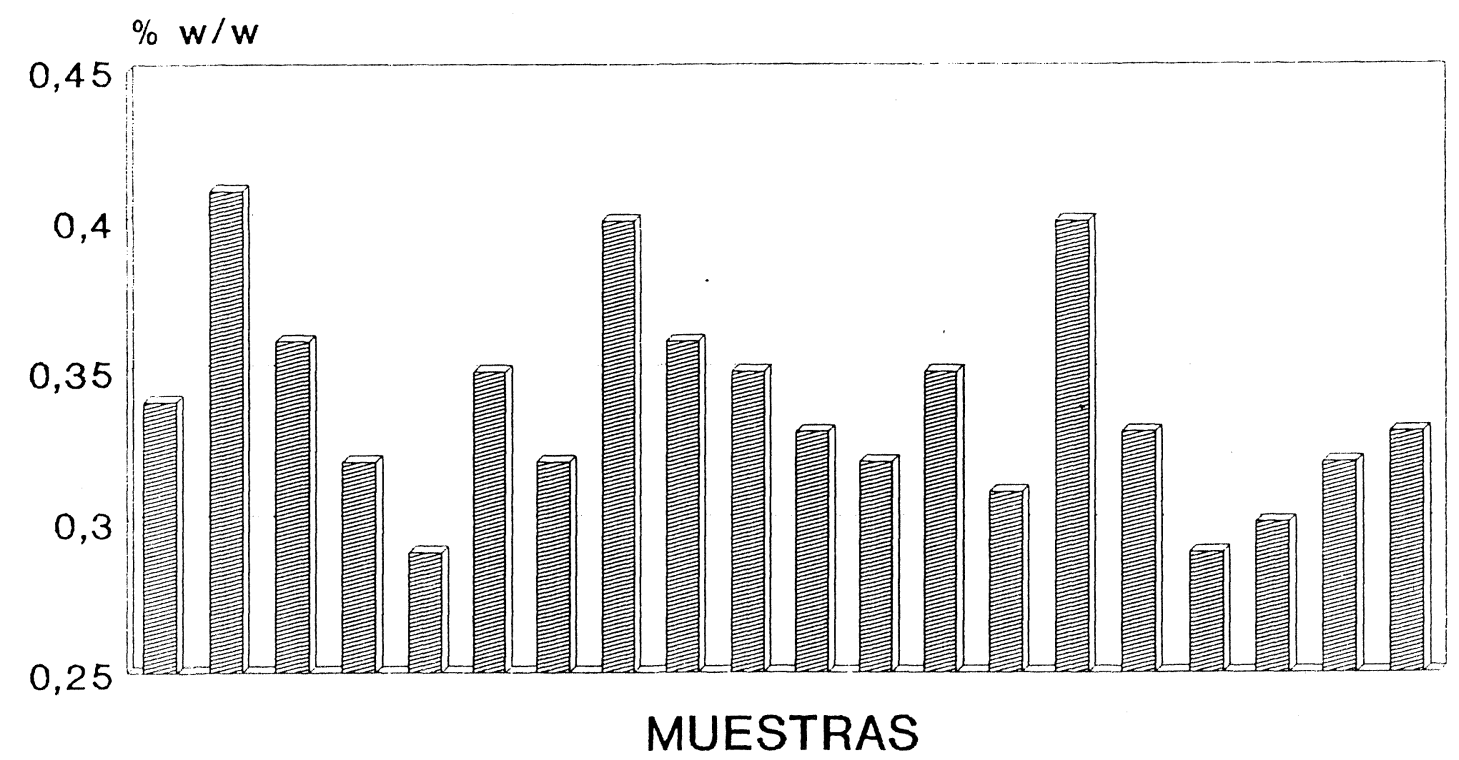

Figura 7 
Los geles estudiados exhibían, en la etiqueta, las siguientes concentraciones, (expresadas en \% en peso):

\section{Geles de baño:}

Bronopol: 0,10\%

Myacide: 0,05\%

\author{
Jabones sólidos: \\ Irgasán: 0,30\% \\ Myacide: $0,05 \%$
}

\section{Geles de baño:}

Dietanolamida del ácido 10-undecilénico: 0,35\%

Considerando las concentraciones expresadas en las etiquetas como las máximas que pueden presentar este tipo de compuestos, según B.O.E. n. 995 , de 20 de abril de 1988, de los resultados obtenidos se desprende que tan sólo un $1 \%$ de los geles estudiados presentan una concentración superior, en Bronopol, a la expresada en la etiqueta, y en todo caso, no sobrepasa el límite máximo de $20 \%$; el $96 \%$ de los geles contienen este bactericida en una concentración que oscila entre el $65 \%$ y el 90\% del valor expresado.

En el caso del Myacide en geles, el $100 \%$ de las muestras estudiadas presentan concentraciones menores que las expresadas en la etiqueta, y el $100 \%$ de las mismas tienen una concentración superior al $60 \%$ de la concentración máxima.

En el caso de los jabones, el $28 \%$ de las muestras superan la concentración máxima expresada para el Irgasán; para el Myacide, el 16\% de las muestras analizadas tiene una concentración superior a la expresada.

En la determinación de dietanolamida del ácido 10-undecilénico en jabones líquidos, se observa que un $25 \%$ de los geles analizados presentan concentraciones superiores a las que se indican en la etiqueta.

Para comprobar la efectividad de las extracciones se utilizaron patrones de adición en todos los casos, comprobándose recuperaciones del $100 \%$ en todos ellos.

Se preparó un patrón de bactericidas distinto para cada una de las muestras a analizar, a fin de que la concentración de los patrones fuese exactamente conocida en cada momento.

\section{DISCUSION DEL METODO PROPUESTO}

\section{Extracción:}

Se utilizaron métodos de extracción sencillos y que requerían el menor número de transformaciones sobre la muestra. Al enfocar este trabajo para su aplicación en un laboratorio de control de calidad optamos por extracciones sólido-líquido y líquido-líquido, siendo rápidas y exactas, huyendo de separaciones por cromatografía en capa fina, que requieren un período de entrenamiento y una precisión en el trabajo excesivamente complejas, a la vez que aumentan considerablemente el tiempo necesario para llevar a cabo el análisis.
Teniendo en cuenta que la mayoría de los bactericidas son poco solubles en disolventes apolares, se eligió el éter etílico, por su parcial polaridad, como disolvente extractor en vez de cloroformo, benceno o incluso hexano como detalla la bibliografía "Gabriel (1974)", "Karleskind (1972)", "Liem (1976)", "Liem (1977)", "Wilson (1975)", "Manowitz (1969)".

Las extracciones líquido-líquido para jabones líquidos presentaba el grave problema de formación de emulsiones. Para solucionar este problema se utilizó una disolución concentrada de electrólito $(\mathrm{NaCl} 20 \% \mathrm{w} / \mathrm{w})$ que aumenta la diferencia de polaridades entre los dos disolventes consiguiendo de esta forma una interfase nítida.

En cuanto a las extracciones sólido-líquido se ensayó con diversos tiempos de extracción llegando a la conclusión de que un periodo de tres horas (unos 20 ciclos) era suficiente para la extracción total de los compuestos bactericidas.

La extracción de la amida del ácido 10-undecilénico por transformación previa y directa en el éster metílico correspondiente resultó ser el método más adecuado, ya que las condiciones de esterificación tan solo son capaces de hidrolizar las amidas presentes en la muestra, reduciendo el problema de la extracción a la vez que obtenemos el derivado óptimo para la cromatografía. La extracción de este derivado del resto de los productos de reacción también se hace con éter etílico, lo cual favorece la utilización del mismo disolvente extractor en todos los casos.

\section{Derivatización:}

Se emplearon dos técnicas de derivatización distintas: acetilación para Bronopol, Myacide e Irgasán, e hidrólisis con posterior esterificación para la dietanolamida del ácido 10-undecilénico.

El empleo de la técnica de acetilación en los compuestos con grupos alcohólicos fue elegido conocido el hecho de que los reactivos silanizantes son significativamente más caros que los empleados para la acetilación, siendo además estos últimos de uso común en cualquier laboratorio.

La elección de la formación del éster metílico del ácido undecilénico viene dada por dos razones fundamentales: por un lado, procediendo a formar un derivado del ácido, se abarca el análisis de otros posibles derivados del mismo, por otro, se consigue la extracción del bactericida, al formar en la misma matriz un derivado apolar, que puede ser extraído fácilmente por medio de extracción líquido-líquido, como se describe en el desarrollo experimental.

\section{Técnica analítica:}

Se eligió la técnica de cromatografía en fase gaseosa por ser de uso común en las empresas que fabrican este tipo de productos, mucho más frecuentemente que la de HPLC e incluso que la espectrofotometría visible-UV. 


\section{Recuperación:}

La recuperación completa de los bactericidas fue comprobada en todas las técnicas. En la extracción sólido-líquido se realizaron experiencias con soxhlets de distintos tamaños y con diferentes tiempos de extracción, comprobándose que para las condiciones elegidas la recuperación era completa. La recuperación en la extracción líquido-líquido fue demostrada por medio de un patrón de adición.

Por último, la extracción de la amida del ácido 10-undecilénico es completa ya que como disolución patrón se emplea la disolución comercial, realizando sobre ella las mismas transformaciones que sobre la muestra a analizar y utilizando en todo caso un exceso considerable de reactivo para asegurar la completa esterificación del ácido.

\section{CONCLUSIONES}

1. Se encuentra que los métodos de caracterización y posterior cuantificación de bactericidas descritos en la bibliografía no son lo suficientemente rápidos y aplicables a un laboratorio común de control de calidad.

2. Se desarrolla un método de análisis de estos bactericidas más rápido que los métodos de los que se disponía hasta el momento y tan seguro como estos, utilizando la cromatografía en fase gaseosa como técnica instrumental.

3. Se concluye que los métodos de derivatización óptimos para los compuestos estudiados son: acetilación para Bronopol, Myacide e Irgasán, e hidrólisis con posterior estirificación para la amida del ácido 10-undecilénico.

4. El método analítico ensayado para la amida del ácido undecilénico es aplicable a otros derivados del ácido que pudieran ser utilizados como bactericidas.

5. El método analítico propuesto para la determinación en jabones sólidos y líquidos puede ser aplicado a otro tipo de formulaciones cosméticas con solo ajustar el método de extracción, lo cual justifica el título del presente trabajo.

\section{BIBLIOGRAFIA}

Ackman, R.G. and Burguer, R.D., (1963).- "Quantitative GLC determination of volatile fatty acids in aqueous media".- An. Chem. 35, 647-653.

Berode, M., Neumeyer, W.U. and Mirimaniff, A. (1974).- "Microdosage du mercure total et du mercure inorganique dans l'urine par absorption atomique sans flamme et étude Chromatographique sur couche mice". Mitt. Geb. Lebensdm. Hyg. 65, 427-440.

B.O.E. n. ${ }^{9} 95$, miércoles 20 de abril de 1988, 12041

Elving, P.J., Warshofsky, B., Shoemaker, E. and Margolit, J. (1948)."Determination of glycerol in fermentation residues".- An. Chem. 20, 29-32.

Gabriel, D.M. (1974).- "Specialized techniques for the analysis of cosmetics and toiletries".- J.S.C.C. 25, 33-39.

Karleskind, A. Valmalle, G. and Wolf, J.P. (1972).- "Identification et dosage des bactericides dans les savons de toilette".- Rev. Fr. Corps Gras 19, 297-233

Lee, S. and Puttnam, N.A. (1965).- "Gas Cromatography determination of chain-length distribution in fatty acids etanolamides".- J.A.O.C.S. 42, 744.

Liem, D.H. (1976).- "Analysis of cosmetics regard to legislation".- Thesis Agric. Univ. Wageningen, The Nederlands.

Liem, D.H. (1977) - "Analysis of antimicrobial compounds in cosmetics". Cosmetics and toiletries 92, 59-72.

Manowitz, M. (1969).- "Cosmetics preservatives in Desinfection, Sterilization and Preservation". - C.A. Lawrence and S.S. Block Eds., Lee and Febiger., Philadelphia, 559.

Marzulli, F.N., and Maibach, M.J. (1973).- "Antimicrobial experimental contact sensitazation on man".- J. Soc. Cosmet. Chem. 24, 399-410.

Montarella, L. and Galliardi, L. (1988).- "Analysis of preservatives in cosmetics".- International Laboratory, nov. 1988, 40-52.

Metcalfe, L.D. and Schmidt. (1959).- Anal. Chem. 31, 307-321.

Peisker, K.V. (1964).- "A rapid semi-micro method for preparation of methyl esters from tryglicerides using Chloroform, Methanol and Sulphuric acid".- J.A.O.C.S. 41, 87-97.

Shepard, P.E. and Wilson, C.H. (1974).- "Fluorometric determination of formaldehide relasing substances in cosmetics".- J.S.C.C. $25,655-670$.

Simon, G.A. (1978).- "Current problems in Dermatology".- Vol 7 "Skin: Drug application and evaluation of enviroment hazards". Series Editor J.W.H., Mali, S. Karger, Base.

Wilson, C.H. (1975).- "Identification of preservatives in cosmetic products by TLC".- J.S.C.C. $26,75-84$.

(Recibido: Junio 1991) 